\title{
Review
}

$\underset{\substack{\text { Urologia } \\ \text { Intemationolis }}}{\text { and }}$

Published online: March 12, 2010

\author{
Vanessa Sandima \\ Denise A. Pereira ${ }^{a}$ \\ Antonio A. Ornellas ${ }^{b}$ \\ Gilda Alves ${ }^{a}$
}

aLaboratório de Genética Aplicada,

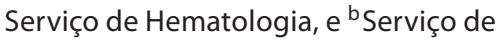
Urologia, Hospital do Câncer I, Instituto Nacional do Câncer, Rio de Janeiro, Brasil

\section{Renal Cell Carcinoma and Proteomics}

\section{Key Words}

Renal cell carcinoma • Proteomics technology • Mass spectrometry

\section{Abstract}

Renal cell carcinoma (RCC) represents $3 \%$ of adult malignancies. About $30 \%$ of RCC patients develop metastatic disease. So far, drugs cannot significantly increase the survival of these patients. We present a recent review of proteomics and RCC. Proteomic technologies have been used in the research to discover new markers of RCC that might increase survival. Furthermore, newly discovered markers cannot increase patient survival, rather their prognostic value supporting therapeutic decisions or new agents targeted at these new markers. More research is required to develop proteomic technologies and biomarkers for identification and validation.

Copyright $\odot 2010$ S. Karger AG, Basel

\section{Introduction}

Renal cell carcinoma (RCC) is a rare solid tumor, but it is the most common cancer of the kidney, it accounts for about $3 \%$ of all adult malignancies $[1,2]$. The main histological subtypes are: clear cell, papillary and chro- mophobe RCC which account for around 75, 15 and 5\% of cases, respectively [3]. Since RCC can become quite large before causing any symptoms, the appearance of symptoms such as gross hematuria and abdominal pain or discomfort often indicates an advanced stage of the disease [4]. Localized RCC can be treated by surgery, but $30 \%$ of the patients develop metastatic disease [5]. Around $40 \%$ of the patients have locally advanced or metastatic disease at the time of diagnosis. Thereafter, the therapeutic options are limited due to a lack of sensitivity to chemotherapy and radiotherapy. The prognosis of patients with metastatic RCC is poor with a 5-year survival rate lower than $10 \%$ [3].

While DNA is the information archive, proteins do the work for the cell. It has been shown that direct gene expression is only responsible for a small part of the complexity of a living organism [6]. Proteomics is the largescale study of proteins, and is associated traditionally with displaying a large number of proteins from a given cell line or organism on two-dimensional gel electrophoresis (2DE) [7-10].

With the accumulation of vast amounts of DNA sequences, it is now believed that merely having the complete sequences of a genome is not sufficient to elucidate the biological function. Curiously, there is no strict linear relationship between genes and the protein complement or 'proteome' of a cell. Proteomics is complementary to

\section{KARGER}

Fax +4161306 1234

E-Mail karger@karger.ch

www.karger.com (c) 2010 S. Karger AG, Basel

$0042-1138 / 10 / 0844-0373 \$ 26.00 / 0$

Accessible online at:

www.karger.com/uin
Vanessa Sandim Siqueira

Serviço de Hematologia, Hospital do Câncer I, Instituto Nacional do Câncer Praça da Cruz Vermelha $\mathrm{N}^{\circ} 23,6^{\circ}$ andar, Centro

Rio de Janeiro, RJ 20.230-130 (Brasil)

Tel. +55212506 6622, Fax +55 212509 7844, E-Mail vsiqueira@inca.gov.br 
genomics, because it focuses on the gene products, which are the active agents in cells. For this reason, proteomics directly contributes to drug development and almost all drugs are directed against proteins [7].

Proteomics uses a rapidly evolving group of technologies to identify, quantify and characterize a global set of proteins [11]. Some of these techniques are 2DE, mass spectrometry (MS), isotope coded affinity tags, protein chip arrays and surface-enhanced laser desorption/ionization (SELDI) aiming to comprehensively profile the expressed proteins (proteome) in a particular system [6].

\section{Proteomics and RCC}

The proteome is the set of proteins expressed by a genome (set of DNA sequences) under certain conditions of time, space, pathological condition and external stimuli [12]. The part of the proteome that studies the biological fluids is the secretome. This term was first used by Tjlasma et al. [13] referring to proteins secreted by the bacterium Bacillus subtilis. This term has been applied more broadly referring to proteins found in biological fluids associated with diseases.

Proteomic technologies used in this approach involve expression of proteins, bioinformatics, and functional proteomics. The 2DE gel was first described by O'Farrel in 1975 [14]. This technique allowed protein separation according to the isoelectric point on the first dimension and to molecular weight on the second. In this technique, we analyzed the differently expressed proteins by the spot staining intensity [15].

Proteomics based on 2DE has recently been optimized with the development of difference gel electrophoresis (DIGE). In DIGE-based proteomics, the experimental and control samples derivatized with different fluorophores and are run in the same gel, thereby minimizing technical variation [16].

Another way to separate proteins is by liquid chromatography (LC); it provides a powerful fractionation method compatible with virtually any mass spectrometer. LC columns can separate large amounts of protein fraction with high resolution [17]. As opposed to 2DE, where samples are separated at the protein level, LC-MS analysis is mostly performed at the peptide level. For analysis of highly complex protein mixtures a multidimensional separation is often applied, where the first dimension of separation can be performed either at the protein level or at the peptide level [18].
The identification of proteins can be done by MS. A simplified definition of a mass spectrometer is an instrument that measures the molecular weight of an ion with high accuracy. In general, this precision is so great that it permits identification of proteins from measurement of masses of peptides derived from trypsin digestion, recognizing that trypsin cuts proteins at specific sites, namely at lysine and arginine residues. A mass spectrometer consists of an ion source, a mass analyzer that measures the mass-to-charge ratio $(\mathrm{m} / \mathrm{z})$ of charged chemical species, and a detector that registers the number of ions at each $\mathrm{m} / \mathrm{z}$ value [16].

The main components of a mass spectrometer are the ionization source and the mass analyzer. Electrospray ionization (ESI) and matrix-assisted and surface-enhanced laser desorption/ionization (MALDI/SELDI) are the two most commonly used techniques to ionize proteins or peptides for mass spectrometric analysis. There are four basic types of mass analyzers currently used in proteomics research: ion trap, time of flight (TOF), quadrupole, and Fourier transform ion cyclotron analyzers. MALDI is usually coupled with TOF analyzers, which measure the mass of intact peptides, whereas ESI has been coupled mostly with ion traps and triple quadrupole instruments and is used to generate fragment ion spectra selected precursor ions $[19,20]$. Surface-enhanced laser desorption/ionization TOF MS (SELDI-TOF/MS) as well as capillary electrophoresis coupled with MS (CE-MS) are promising techniques.

SELDI-TOF MS is an easy-to-use system with an automation and high throughput. Only a small volume of sample is required for SELDI-TOF MS. SELDI reduces the complexity of samples by fractionation based on selective interactions of polypeptides with different immobilized matrices. These active surfaces can be reverse-phase or ion exchange materials, ligands, and specific ions. Due to the selectivity and the limited capacity of the active surface, only a small fraction of the polypeptides in a sample binds to the surface of the SELDI chip, facilitating the subsequent MS analysis of the originally highly complex sample $[11,17,21]$.

CE-MS provides high separation efficiency in small volumes. Proteins are resolved according to their elution time from the CE and the mass of the protein in the MS. Its use for identifying polypeptide biomarkers in urine has increased [11]. This approach is based on CE in the fractionation device coupled with a mass spectrometer. $\mathrm{CE}$ separates proteins based on migration in the electrical Weld $(300-500 \mathrm{~V} / \mathrm{cm})$ with high resolution. CE-MS has the advantage of providing fast and robust separation at 
high resolution and is compatible with most buffers and analytes and it provides a stable constant flow, thereby avoiding gradients in the buffer that may otherwise hamper detection by MS [21]. A diagram of how these technologies can be applied in RCC is shown in figure 1 .

\section{RCC versus Proteomics}

Some published studies analyzed the RCC proteome employing different proteomic technologies (2D/MS, SELDI, ESI-MS/MS and LC-MS/MS) and sample types (urine, serum and tissues). A comparative analysis by 2DE of normal kidney and 10 cases of RCC identified 4 peptides absent in RCC highlights ubiquinol cytochrome $\mathrm{C}$ reductase (UQCR) and NADH-oxido-ubiquinone reductase I mitochondrial complex. These results suggested that the downregulated expression of UQCR and $\mathrm{NADH}$-ubiquinone oxidoreductase mitochondrial complex I contribute to the genesis and/or development of RCC [22].

It was observed by $2 \mathrm{DE}$ that proteins were differentially expressed in normal tissue and kidney tissue with RCC. In RCC tissue, 66 proteins were found in increasing or decreasing concentration. Only 8 proteins were identified by peptide map fingerprinting (vimentin, aminoacylase-1, enoyl-CoA hydratase, aldehyde reductase, agmatinase, $\alpha_{1}$-antitrypsin precursor, tropomyosin $\alpha_{4}$-chain and ketohexokinase). Vimentin is a protein of the cytoskeleton that is overexpressed in samples of RCC compared with samples of normal tissue, in addition to different expressions in different subtypes of RCC. This protein is often associated with cell differentiation, invasion, migration and the potential of metastatic tumors. The $\alpha_{1^{-}}$ antitrypsin enzyme precursor's main function is to release elastases from leukocytes in inflammation; this enzyme is overexpressed in tissues with RCC. Highly active aminoacylase- 1 is found in the kidneys, is often involved in process of detoxification and has a lower expression in some types of lung tumors. Enzymes enoyl-CoA hydratase (mitochondrial $\beta$-oxidation), aldehyde reductase (oxi-reduction enzyme), tropomyosin $\alpha_{4}$-chain (cytoskeleton protein), ketohexokinase (also called fructokinase; it catalyzes the phosphorylation of fructose to fructose 1-phosphate) and agmatinase were expressed in the subsamples [23].

Samples of tissue from 4 patients with RCC were analyzed using 2DE and MS. Thirty-one proteins differentially expressed were identified. Some of these proteins were confirmed by Western blot and immunohistochem-

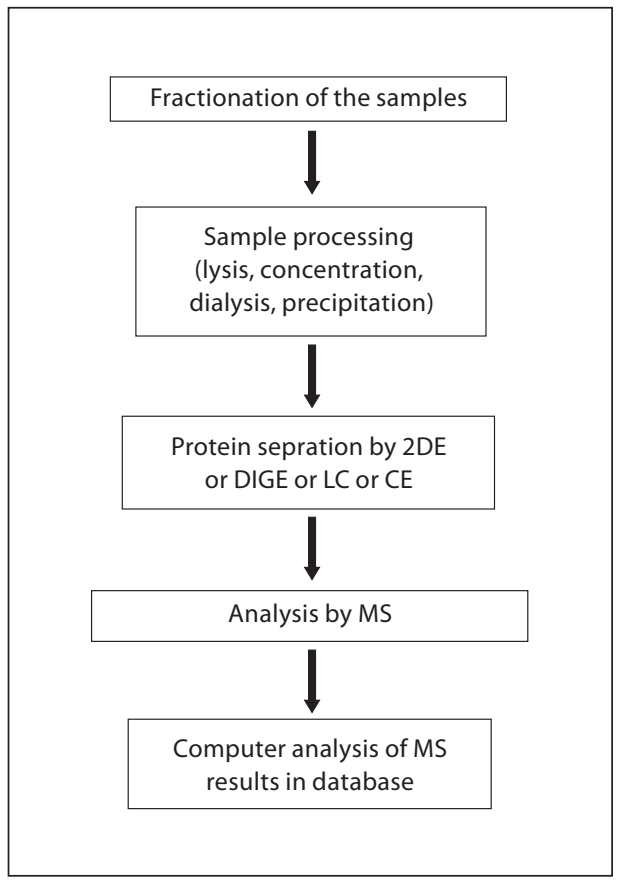

Fig. 1. Diagram of sample analysis by proteomic technologies.

istry, and they were compared with results already published [24]. Using programs of bioinformatics, the metabolic processes in which these proteins are involved have been identified. Urine analyses of these patients and controls showed that sorbitol was the only metabolic product that had a five times higher concentration in the urine of patients with RCC [25].

Okamura et al. [26] focused on upregulated proteins in cancerous tissues since these proteins are thought to be potential diagnostic biomarkers. Among the upregulated proteins, the authors selected galectin-1 and CNDP2 and validated their proteomics data since they have not been studied in relation to RCC. Both proteins showed high expression levels in RCC tissues and occurred with high frequency in RCC patients; galectin-1 in 11 of 14 patients (79\%) and CNDP2 in all 9 patients (100\%) studied.

In CAL 54, a human RCC cell line, the protein expression profile was analyzed by $2 \mathrm{DE} / \mathrm{MS}$, and it was observed that protein pro-metalloproteinase-7 was overexpressed in the cell line tumor secretome. The protein was analyzed in 30 serum samples from RCC patients and 30 samples from normal patients. The results showed that with a sensitivity of $93 \%$ and specificity of $75 \%$ the proMMP-7 is increased in the serum of patients with RCC $(\mathrm{p}<0.0001)$ [27]. 
The plasma protein expression profile by SELDI from 56 patients undergoing therapy for RCC with IL-2 after radical nephrectomy was analyzed. The authors identified protein differences between patients with good response to treatment and those who did not respond to treatment. The authors suggested that it is possible to avoid the undesirable side effects of treatment with IL-2 [28].

The urine of patients with RCC, before and after surgery, was analyzed by $2 \mathrm{DE}$. The expression of two proteins after nephrectomy was diminished: the mannanbinding lectin serine protease 2 and, more dramatically, the kininogen, a precursor of protein bradykinin that mediates inflammation and improves vascular permeability. This considerable change in kininogen has been reported in the progression of cancer [29].

A recent study of urine in patients with clear-cell RCC by SELDI-TOF showed that the peak cluster identified was different from those reported. One of the signals used in the cluster was identified as a fragment of uromodulin, but the physiological role of this protein is still uncertain [30].

However, despite these studies, no biological markers that could be screened or used as target therapy have yet been established. But these technologies allowed a breakthrough in the discovery of differentially expressed proteins specific to RCC.

\section{Conclusions}

There is a need for more research in RCC and proteomic technologies for the identification of biomarkers that allow the development of methods for early diagnosis, detection of occult metastatic disease, monitoring response during treatment and development of new target therapeutic drugs directed at specific proteins.

\section{References}

1 Mancini V: Current insight in renal cell cancer pathology. Urol Oncol 2008;26:225-238.

12 Pouessed D, Ouline S: Targeted therapies in metastatic renal cell carcinoma: the light at the end of the tunnel. Expert Rev Anticancer Ther 2006;6:1761-1767.

-3 Banks RE, Craven RA, Harnden P, Madaan S, Joyce A, Selby PJ: Key Clinical issues in renal cancer: a challenges for proteomics. World J Urol 2007;25:37-56.

4 Hara T, Honda K, Ono M, Naito K, Hiroashi S, Yamada T: Identification of 2 serum biomarkers of renal cell carcinoma by surface enhanced laser desorption/ionization mass spectrometry. J Urol 2005;174:1213-1217.

5 Skates S, Hiopoulos O: Molecular markers for early detection of renal carcinoma: investigative approach. Clin Cancer Res 2004;10: 6296s-6301s.

6 Alpantaki K, Tsiridis E, Pape HC, Giannoudis PV: Application of clinical proteomics in diagnosis and management of trauma patients. Injury 2007;38:263-271.

7 Pandey A, Mann M: Proteomics to study genes and genomes. Nature 2000;405:837846.

${ }_{8}$ Wilkins MR, et al: From proteins to proteomes: large scale protein identification by two-dimensional electrophoresis and amino acid analysis. Biotechnology (NY) 1996;14: 61-65. -9elis J, et al: Human 2-D PAGE databases for proteome analysis in health and disease: http://biobase.dk/cgi-bin/celis. FEBS Lett 1996;398:129-134.

10 Anderson NG, Anderson NL: Twenty years of two-dimensional electrophoresis: past, present and future. Electrophoresis 1996;17: 443-453.

11 Janech MG, Raymond JR, Arthur JM: Proteomics in renal research. Am J Physiol Renal Physiol 2007;292:F501-F512.

12 Wasinger VC, Cordwell SJ, Cerpa-Poljak A, Yan JX, Gooley AA, Wilkins MR, Duncan MW, Harris R, Williams KL, HumpherySmith I: Progress with gene-product mapping of the Mollicutes: Mycoplasma genitalium. Electrophoresis 1995;16:1090-1094.

-13 Tjalsma H, Bolhuis A, Jongbloed JD, Bron S, van Dijl JM: Signal peptide-dependent protein transport in Bacillus subtilis: a genomebased survey of the secretome. Microbiol Mol Biol Rev 2000;64:515-547.

14 O’Farrell PH: High resolution two-dimensional electrophoresis of proteins. J Biol Chem 1975;250:4007-4021.

15 Cutillas P, Burlingame A, Unwin R: Proteomics strategies and their application in studies of renal function. News Physiol Sci 2004;19:114-119.

16 Hoorn EJ, Hoffert JD, Knepper MA: The application of DIGE-based proteomics to renal physiology. Nephron Physiol 2006;104:6172.
17 Theodorescu D, Mischak H: Mass spectrometry based proteomics in urine biomarker discovery. World J Urol 2007;25:435-443.

-18 America AHP, Cordewener JHG: Comparative LC-MS: A landscape of peaks and valleys. Proteomics 2008;8:731-749.

19 Barratt J, Topham P: Urine proteomics: the present and future of measuring urinary protein components in disease. CMAJ 2007; 177:361-368

20 González-Buitrago JM, Ferreira L, Lorenzo I: Urinary proteomics. Clin Chim Acta 2007; 375:49-56.

-21 Thongboonkerd V: Practical points in urinary proteomics. J Proteome Res 2007;6: 3881-3890.

22 Sarto C, Marocchi A, Sanchez JC, Giannone D, Frutiger S, Golaz O, Wilkins MR, Doro G, Cappellano F, Hughes G, Hochstrasser DF, Mocarelli P: Renal cell carcinoma and normal kidney protein expression. Electrophoresis 1997;18:599-604.

23 Hwa JS, Park HJ, Jung JH, Kam SC, Park HC, Kim CW, Kang KR, Hyun JS, Chung KH: Identification of proteins differentially expressed in the conventional renal cell carcinoma by proteomic analysis. J Korean Med Sci 2005;20:450-455.

24 Takahashi M, Rhodes DR, Furge KA, Kanayama H, Kagawa S, Haab BB, Teh BT: Gene expression profiling of clear cell renal cell carcinoma: gene identification and prognostic classification. Proc Natl Acad Sci USA 2001;98:9754-9759. 
25 Perroud B, Lee J, Valkova N, Dhirapong A, Lin PY, Fiehn O, Kültz D, Weiss RH: Pathway analysis of kidney cancer using proteomics and metabolic profiling. Mol Cancer 2006;5: 64.

26 Okamura N, Masuda T, Gotoh A, Shirakawa T, Terao S, Kaneko N, Suganuma K, Watanabe M, Matsubara T, Seto R, Matsumoto J, Kawakami M, Yamamori M, Nakamura T, Yagami T, Sakaeda T, Fujisawa M, Nishimura O, Okumura K: Quantitative proteomic analysis to discover potential diagnostic markers and therapeutic targets in human renal cell carcinoma. Proteomics 2008; 3194-3203.
27 Sarkissian G, Fergelot P, Lamy PJ, Patard JJ, Culine S, Jouin P, Rioux-Leclercq N, Darbouret B: Identification of pro-MMP-7 as a serum marker for renal cell carcinoma by use of proteomic analysis. Clin Chem 2008;54: 574-581.

28 Jones J, Otu HH, Grall F, Spentzos D, Can $\mathrm{H}$, Aivado M, Belldegrun AS, Pantuck AJ, Libermann TA: Proteomic identification of interleukin-2 therapy response in metastatic renal cell cancer. J Urol 2008;179:730-736.
9 Pieper R, Gatlin CL, McGrath AM, Makusky AJ, Mondal M, Seonarain M, Field E, Schatz CR, Estock MA, Ahmed N, Anderson NG, Steiner S: Characterization of the human urinary proteome: a method for high-resolution display of urinary proteins on two-dimensional electrophoresis gels with a yield of nearly 1400 distinct protein spots. Proteomics 2004;4:1159-1174.

30 Bosso N, Chinello C, Picozzi SCM, Gianazza E, Mainini V, Galbusera C, Raimondo F, Perego R, Casellato S, Rocco F, Ferrero S, Bosari S, Mocarelli P, Kienle MG, Magni F: $\mathrm{Hu}-$ man urine biomarkers of renal cell carcinoma evaluated by ClinProt. Proteomics Clin Appl 2008;2:1036-1046. 